\title{
CHAMEM O CHEF! O PRINCIPAL RECURSO ESTRATÉGICO DOS RESTAURANTES GASTRONÔMICOS: ESTUDO DE MULTICASOS NA AMÉRICA LATINA
}

\author{
CALL THE CHEF! THE PRINCIPAL STRATEGIC RESOURCE OF GASTRO RESTAURANTS: MULTI CASE- \\ STUDY IN LATIN AMERICA
¡LLAMEN AL CHEF! EL PRINCIPAL RECURSO ESTRATÉGICO DE LOS RESTAURANTES GASTRONÓMICOS: ESTUDIO DE MULTICASOS EN AMÉRICA LATINA

\author{
Viviane Santos Salazar \\ Professora Adjunta I do Departamento de Hotelaria e Turismo da UFPE \\ Doutora em Administração pela UFPE \\ viviane_salazar@yahoo.com.br
}

\author{
Walter Fernando Araújo de Moraes \\ Professor Titular no Departamento de Ciências Administrativas \\ Universidade Federal de Pernambuco \\ PhD - University of Texas at Austin \\ wfam1950@gmail.com
}

Yákara Vasconcelos Pereira

Professora Adjunta III da Universidade Federal Rural do Semiárido Doutora em Administração UFPE yakarav@gmail.com

Artigo Submetido em: 28/11/2016 Artigo Aceito em: 23/03/2017

\begin{abstract}
RESUMO: O objetivo deste trabalho é o de analisar como o recurso humano chef de cozinha pode gerar vantagem competitiva sustentável para restaurantes gastronômicos na América Latina. Para atingir tal objetivo, a metodologia utilizada foi de natureza qualitativa baseada em múltiplos estudos de casos. As técnicas usadas para coletar os dados foram: entrevistas semiestruturadas realizadas com os chefs de cozinha e análise documental de cardápios, matérias e livros. Os dados foram analisados por meio da análise de conteúdo com o auxílio do software Atlas t.i. Os resultados indicaram que o chef de cozinha é fundamental para qualquer restaurante que almeje ser listado em algum guia gastronômico reconhecido. Este recurso humano foi identificado como primordial para a concepção e consecução das estratégias dos restaurantes e por meio da combinação e da complementariedade de recursos estratégicos, quais sejam: cultura organizacional, recursos financeiros, inovação e criatividade, recursos humanos, recursos físicos (equipamentos e utensílios), reputação e redes de relacionamento. A partir dos resultados, identificou-se que os chefs criaram uma identidade distinta para suas empresas, diferenciando-os da concorrência e gerando vantagem competitiva sustentável.
\end{abstract}

PALAVRAS-CHAVE: Recurso; Chef de cozinha; restaurante.

ABSTRACT: The objective of this study is to analyse chefs can generate sustainable competitive advantage for gastro restaurants in Latin America. In order to achieve that goal, a qualitative methodology was adopted based on multiple case studies. The techniques used to collect data were semi-structured interviews with chefs and documental analysis of menus, news articles and books. Data was analysed using content analysis with the help of the Atlas.TI software. The results indicated that the chef is the key to any restaurant that expects to be listed on a well-recognized gastronomic guide. This human resource has been identified as essential for the design and introduction of strategies, using the combination and complementarity of strategic resources, such as: organizational culture, financial resources, innovation and creativity, human resources, physical infrastructure, reputation and networking. Based on the results, it was concluded that chefs have created a distinct identity for their businesses, creating competitive edge and creating sustainable competitive advantage. 
RESUMEN: El objetivo de este trabajo es analizar cómo el recurso humano chef de cocina puede generar una ventaja competitiva sostenible para restaurantes gastronómicos en América Latina. Para alcanzar tal objetivo la metodología utilizada fue de naturaleza cualitativa, basada en múltiples estudios de casos. Las técnicas usadas para recolectar los datos fueron entrevistas semiestructuradas realizadas con los chefs de cocina y el análisis documental de menús, materiales periodísticos y libros. Se analizaron los datos por medio del análisis de contenido con el auxilio del software Atlas ti. Los resultados indicaron que el chef de cocina es fundamental para cualquier restaurante que ambicione figurar en alguna guía gastronómica reconocida. Este recurso humano fue identificado como primordial para la concepción y consecución de las estrategias de los restaurantes y por medio de la combinación y de la complementariedad de recursos estratégicos, a saber: cultura organizacional, recursos financieros, innovación y creatividad, recursos humanos, recursos físicos (equipamientos y utensilios), reputación y redes de relaciones. A partir de los resultados se identificó que los chefs crearon una identidad distinta para sus empresas, diferenciándolas de la competencia y generando ventaja competitiva sostenible.

PALABRAS CLAVE: Recurso; Chef de cocina; Restaurante.

INTRODUÇÃO

omo área de investigação científica, a administração estratégica
surgiu na década de 60 com os escritos de Chandler, Andrews administração e pode ser investigada com foco em três dimensões distintas que interagem entre si: contexto, conteúdo e processo (De Wit \& Meyer, 2004; Pettigrew, 1987).

Na dimensão conteúdo, como uma corrente teórica robusta, a Resource Based View (RBV) surgiu no início da década de 90 com o artigo seminal de Barney (1991), e durante a década de 90 os estudos sobre a RBV cresceram em quantidade e qualidade. Esta teoria apregoa que as empresas serão capazes de ter desempenho superior se possuírem recursos raros, valiosos, de difícil imitação e se forem capazes de explorar estes recursos (Wernerfelt, 1984; Barney, 1991; Barney, 2002).

Porém, uma das críticas à RBV é que a literatura é muito generalista sobre os méritos dos recursos, e não considera o contexto e a indústria nos quais os recursos podem ter valor para a empresa (Miller \& Shamsie, 1996), além de não determinar também o tempo e a causa do valor de um recurso (Amit \& Schoemaker, 1993). Com vistas a sanar essa crítica e contribuir para o avanço teórico e prático da RBV, este artigo tem como objeto empírico de pesquisa os chefs de cozinha de restaurantes gastronômicos, gourmets ou de alta gastronomia da América Latina. A escolha do campo de pesquisa justifica-se 
pela alta gastronomia ser o ponto alto da indústria de restaurantes, pois tem funções chaves, a saber: aponta as tendências do setor, constrói uma imagem e indica padrões de qualidade que guiarão toda a indústria de alimentação fora do lar (Leschziner, 2007; Surlemont \& Johnson, 2005). Por restaurante gastronômico ou gourmets (Lewis, 1981) entende-se o estabelecimento que oferece cardápios e serviços dispendiosos e está voltado geralmente para o lazer (Walker \& Lundberg, 2003).

Parte-se do pressuposto que o chef de cozinha é, na atualidade, o recurso estratégico mais importante de um restaurante gastronômico, mas nem sempre esse recurso teve valor. O chef de cozinha ganhou notoriedade durante o movimento francês da nouvelle cuisine, antes, porém, os profissionais que exerciam o ofício de cozinheiro possuíam baixo status (Scavone, 2007). Foi Fernand Point, chef do restaurante La Pyramide, o responsável por dar uma nova dignidade ao chef de cozinha. Ele foi o primeiro a sair da cozinha e ingressar no salão, conversar com os clientes e projetar publicamente a figura do chef (Atala \& Dória, 2008). Houve assim, nos serviços de alta gastronomia, uma personificação dos restaurantes a partir do trabalho dos chefs e a consequente identificação do cliente com o resultado deste trabalho (Brandão \& Pereira, 2010). Os chefs passaram a ser a atração principal dos restaurantes e suas criações atraem a atenção dos consumidores, sendo este fascínio um fenômeno global (Brasil Food Trends 2020, 2010). Assim, este trabalho busca responder a seguinte pergunta de pesquisa: como o recurso estratégico chef de cozinha de restaurantes gastronômicos da América Latina pode gerar vantagem competitiva sustentável?

\section{RBV E OS RECURSOS}

As primeiras ideias que embasam a RBV surgiram a partir dos escritos de economistas como Edith Penrose, David Ricardo e Joseph Schumpeter (Grant, 1991; Barney \& Hesterly, 2004), apesar de nenhum deles tratar especificamente da relação entre a posse dos recursos e o desempenho superior de uma empresa. Barney (1991) foi o primeiro autor a relacionar os recursos heterogêneos das empresas à vantagem competitiva sustentável (VCS). Um recurso potencialmente vantajoso e competitivo deve apresentar quatro atributos: valioso no sentido de explorar oportunidades e proteger-se das ameaças; raro; impossível de imitar; e não deve existir equivalente para este recurso. 
Por recursos entendem-se todos os inputs do processo produtivo e que são a unidade básica de análise da RBV (Grant, 1991; Vasconcelos \& Cyrino, 2000). Geralmente os recursos são classificados em duas grandes categorias: tangíveis e intangíveis (Galbreath \& Galvin; 2004). Nestas duas grandes classes de recursos há ainda uma subdivisão dos recursos em físicos, financeiros, humanos, organizacionais, relacionais tecnológicos e reputacionais (Barney, 1991; Grant, 1991; Pike, Roos \& Marr, 2005). Os recursos por si só são incapazes de gerar vantagem competitiva sustentável. Para tal é necessário que os mesmos tenham alguns atributos ou qualificações. Carneiro, Cavalcanti e Da Silva (1999) asseguram, porém, não haver consenso quais sejam esses atributos.

Dentre as mais citadas na literatura destacam-se valor, raridade, escassez e não imitabilidade, $O$ valor se refere ao potencial do recurso de explorar oportunidades e/ou neutralizar ameaças do ambiente (Barney; 1991). Outro atributo dos recursos estratégicos é a raridade (Reed \& Defillippi, 1990; Barney, 1991; Peteraf, 1993). Considera-se raro o recurso que é escasso entre os concorrentes atuais e potenciais (Barney; 1991) ou que são específicos da empresa (Reed \& Defillippi, 1990).

A não imitabilidade se refere à desvantagem de custo que os concorrentes terão para obter os recursos estratégicos em comparação às empresas que já os possuem (Barney, 1991). Esta característica se deve a condições históricas únicas, ambiguidade causal e complexidade social (Barney, 1991) ou por barreiras de imitação que decorrem das deseconomias por compressão de tempo, eficiência por massa de recursos, pelo inter-relacionamento entre recursos, pela ambiguidade causal e pela não erosão dos recursos (Dierickx \& Cool, 1989). Este último conceito similar ao conceito de durabilidade proposto por Grant (1991).

Para um recurso serinsubstituível não deve haveroutros recursos que permitam o desenvolvimento das mesmas estratégias, ainda que de um modo diferente, mas que não sejam raros ou imperfeitamente imitáveis (Carneiro, Cavalcanti \& Da Silva, 1999). Ademais os recursos para gerarem vantagem competitiva sustentável devem ser não transparentes ou difíceis de serem reconhecidos e replicáveis (Grant, 1991; Peteraf, 1993) e não comercializáveis (Dierickx \& Cool, 
1989). Por fim, Grant (1991) defende que os recursos estratégicos devem ter apropriabilidade - a captação do valor do recurso deve ser adequada unicamente para a empresa detentora do mesmo; e ter superioridade competitiva.

Apesar de a RBV ser uma teoria de estratégia proeminente (Lockett, Thompson \& Morgenstern, 2009) para explicar a vantagem competitiva das empresas, é também alvo de muitas críticas. Kraaijenbrink, Spender e Groen (2010) enfatizam que apenas três delas devem ser consideradas: (i) os achados empíricos dão pouco suporte à teoria, ou seja, critérios do valor, raridade, imitabilidade e organização (VRIO) nem sempre são necessários ou suficientes para explicar a vantagem competitiva das empresas; (ii) o valor de um recurso é muito indeterminado para gerar teoria útil; e (iii) a ampla definição do que são os recursos, a qual aparentemente pode ser vista como uma força da teoria, revela-se como uma fraqueza na medida em que trata todos os recursos de maneira semelhante.

Dentreosváriostipos de recursos, a literatura defendequeosrecursoshumanos podem se constituir em um dos fatores de vantagem competitiva sustentável de uma empresa (Wright et al., 2001). Nos restaurantes gastronômicos, um dos recursos humanos mais importantes é, na atualidade, os chefs de cozinha.

\section{OS RESTAURANTES E OS CHEFS DE COZINHA}

A figura do chef de cozinha como um empregado ou dono de um restaurante surgiu a partir da Revolução Francesa, quando este serviçal da monarquia saiu dos palácios e foi para Paris trabalhar em restaurantes ou abrir o seu próprio negócio. A partir disso, cada restaurante francês passou a ter um homem que desenvolvia os prazeres da boa mesa, com sofisticação e arte. Mas foi a partir do movimento da nouvelle cuisine que a figura do chef de cozinha passou a ser valorizado e a ser conhecido pelos seus clientes (Hetzel, 2004; Dória, 2006; Durand, Rao \& Monin, 2007). Foi Fernand Point, chef do restaurante La Pyramide e um dos precursores do movimento, o responsável por dar uma nova dignidade ao chef de cozinha. Deve-se a ele a ruptura com o padrão anterior de restringir o chef aos estritos domínios da cozinha. Ele foi o primeiro a sair da cozinha e ingressar no salão, conversar com os clientes e projetar publicamente a figura do chef (Atala \& Dória, 2008). 
Assim, desde então, nos serviços de alta gastronomia houve uma personificação dos restaurantes a partir do trabalho dos chefs de cozinha e a consequente identificação do cliente com o resultado deste trabalho (Brandão \& Pereira, 2010). Os chefs passaram a ser a atração principal dos restaurantes e muito do sucesso ou fracasso dos mesmos está associado à figura deste profissional (Atala \& Dória, 2008; Dória, 2006).

Ao estudarem as principais competências dos chefs de cozinha, Birdir e Pearson (2000) as classificaram em dois grandes grupos: os chefs pesquisadores e os administradores. Os pesquisadores geralmente desenvolvem novos produtos, criam novas receitas e fazem análise e testes com alimentos. Já o chef administrador é aquele que tem conhecimentos administrativos, participa do planejamento estratégico do restaurante e tem habilidades comerciais. Dentre as competências dos chefs pesquisadores, a capacidade de inovar é destacada por vários autores (Horng \& Lee, 2009; Hu, 2010; Ottenbacher \& Harrington, 2007; Ottenbacher \& Harrington, 2008) e de acordo com Ottenbacher e Harrington (2007), pode ser descrito em sete etapas inter-relacionadas.

O processo de inovação tem início com a geração da ideia que compreende as dimensões de produto, fontes de inspiração e as habilidades criativas do chef. Nesta fase a qualidade do produto é um fator crucial para o sucesso dos restaurantes gastronômicos (Balazs, 2002), visto que conhecer a origem dos ingredientes e garantir qualidade e frescor tornaram-se distinção entre restaurantes de alta gastronomia (Murphy \& Smith, 2009; Lane, 2011).

O segundo passo é a triagem das criações, que foi descrita pelos autores como um processo informal, o qual considera a sazonalidade dos produtos, os custos, questões operacionais e de mercado. A terceira etapa é a fase da tentativa e erro - alguns chefs elaboram suas criações apenas no pensamento, depois testam partes separadas e depois toda a receita. Na fase do desenvolvimento do conceito, o chef escreve as instruções de trabalho, de arrumação do prato e fotografa o mesmo. Há também uma pesquisa informal de mercado - conversas com os clientes e o pessoal do salão. A estética e a escolha das louças em que a receita será apresentada são importantes. 
Os testes finais são realizados com o auxílio de outros empregados, como o maitre e o sommelier, além de clientes fiéis e amigos. E segue-se a etapa do treinamento, que é realizado com o pessoal da cozinha e com garçons e maitres. Por fim, ocorre a comercialização do prato propriamente dita.

Já Hu (2010) também relaciona a competência inovadora ao sucesso do restaurante e elenca sete dimensões da inovação: cultura, estética, tecnologia, produto, serviço, gestão e criatividade. A cultura se refere à capacidade do chef de transmitir aspectos culturais por meio das receitas elaboradas, já que o chef é realmente criativo quando consegue materializar sua filosofia (Atala \& Dória, 2008). A estética e o serviço estão relacionados à chamada economia da experiência - o consumo em qualquer bom restaurante vai além de servir uma comida saborosa e deve também proporcionar uma experiência sensorial completa (Schmitt \& Simonson, 2000).

A tecnologia está associada à gastronomia molecular preconizada por Hervé This. A dimensão produto e a criatividade dizem respeito ao conhecimento do chef acerca das técnicas, do desenvolvimento e da apresentação de novos pratos. Por fim, a gestão engloba as competências necessárias ao planejamento, à organização, à liderança e ao controle dos processos produtivos.

Pode-se inferir, portanto, que o chef de cozinha, para gerar vantagem competitiva para o restaurante, deve ter competências inovadoras, mas também competências gerenciais e de liderança. Com relação a esta última competência, Balazs (2002) afirma que, nos restaurantes estrelados franceses, os papéis de liderança dos chefs são: o líder carismático e o arquiteto organizacional. Enquanto o primeiro exerce um papel importante na formação das estratégias e na cultura organizacional, o papel de arquiteto organizacional influencia no modo como a organização lida com seus stakeholders externos e como são desenhadas a estrutura e a operação da empresa.

METODOLOGIA

De modo geral, as pesquisas são formadas por quatro dimensões: o posicionamento ontológico e epistemológico do pesquisador, o método, a técnica de coleta de dados e o modo de análise e interpretação dos dados 
(Creswell, 2010; Flick, 2009). Nesse sentido, a dimensão epistemológica deste trabalho - que se refere ao conhecimento e como ele pode ser obtido - é positivista e a opção metodológica é a pesquisa qualitativa.

Para justificar a escolha desta abordagem, elencam-se: a compreensão do fenômeno no contexto em que ocorre e do qual é parte e a coleta de dados acontece neste contexto; o pesquisador é o instrumento principal para a coleta de dados; a diversidade de dados que podem ser coletados de várias maneiras; a análise de dados é indutiva; a pesquisa busca "captar" o fenômeno em estudo a partir da perspectiva das pessoas nele envolvidas (Godoy, 1995; Creswell, 2007). A abordagem escolhida é a do estudo de caso e pode ser definida também como uma estratégia de investigação, uma metodologia, ou uma estratégia de pesquisa abrangente (Merriam, 1998; Yin, 2010).

A unidade de análise escolhida foi formada pelos chefs de três restaurantes gastronômicos premiados na América Latina - dois no Brasil e um no Peru. Os restaurantes foram escolhidos de acordo com a lista lançada em 2013 dos 50 melhores restaurantes da América Latina publicada pelo guia inglês "The restaurants". Parte-se do pressuposto que estes restaurantes possuem VCS sobre os demais por estarem nesta lista e pelo tempo de sobrevivência no mercado que variou de mais de 40 anos a 5 anos. A sobrevivência no mercado é elencada por Barney (2002) como uma das medidas para se avaliar o desempenho superior.

As técnicas de coleta de dados foram: entrevista semiestruturada e análise de documentos (Patton, 2001; Taylor \& Bogdan, 1984). Alguns detalhes da entrevista estão elencados no Quadro 1 - a descrição (indicando a empresa e a sua função), a formação (grau escolar), o tempo de atuação na organização, a data de realização da coleta dos dados e tempo de entrevista, que perfizeram 221,03 minutos no total.

Quadro 1 - Apresentação dos sujeitos entrevistados

\begin{tabular}{|c|c|c|c|c|c|}
\hline $\begin{array}{c}\text { Nome do } \\
\text { entrevistado }\end{array}$ & Descrição & Formação & $\begin{array}{c}\text { Tempo na } \\
\text { org. }\end{array}$ & Data & Tempo \\
\hline Rodrigo Oliveira & $\begin{array}{c}\text { Chef do Restaurante } \\
\text { Mocotó }\end{array}$ & Chef de Cozinha & 1993 - atual & 02.12 .14 & $64^{\prime} 58^{\prime \prime}$ \\
\hline Alberto Landgraf & $\begin{array}{c}\text { Chef do Restaurante } \\
\text { Epice }\end{array}$ & Chef de Cozinha & 2011 - atual & 04.12 .14 & $61^{\prime} 06^{\prime \prime}$ \\
\hline Diego Muñoz & $\begin{array}{c}\text { Chef do Restaurante } \\
\text { Astrid y Gaston }\end{array}$ & Chef de Cozinha & 2011 -atual & 19.09 .14 & $66^{\prime} 58$ \\
\hline
\end{tabular}


Fonte: Elaboração dos autores (2015).

Por fim, a pesquisa documental também é apropriada para esta pesquisa e foi utilizada. Assim, os dados secundários "[...] coletados por pessoas que não estavam presentes por ocasião da sua ocorrência" (Godoy, 1995:22-23), de forma impressa e digital, foram obtidos com os interlocutores nos momentos das entrevistas, em sites, revistas e publicações da área, em sites institucionais e das três empresas pesquisadas, além de um livro escrito por Gaston Acurio, Ferran Adrià e Ignácio Medina (importante crítico gastronômico espanhol). Ao total foram gerados 104 documentos no ATLAS.ti que compuseram o corpus da pesquisa.

A análise dos dados segue os pressupostos da pesquisa qualitativa, caracterizada pela grande quantidade de informações (Patton, 2001), sendo a codificação uma sistemática de desenvolvimento e refino que ajuda a interpretação dos dados (Taylor \& Bogdan, 1984).

Preocupando-se com isso, adotou-se a análise de conteúdo (Bardin, 1977) para identificar as conexões - relações entre o recurso chef e outros recursos, códigos e categorias - como os chefs geram vantagem competitiva sustentável, as quais estão nas transcrições das entrevistas e nos documentos analisados. A análise dos dados desenvolveu-se fielmente ao método de análise de conteúdo proposto pela autora supracitada, composta por três etapas: (1) pré-análise; (2) exploração do material; (3) tratamento dos resultados e interpretações, considerando a operacionalização no ATLAS.ti.

\section{ANÁLISE DOS RESULTADOS}

Nos três casos estudados pode-se afirmar que o chef de cozinha é o recurso estratégico mais valioso dos restaurantes gastronômicos estudados e pode gerar VCS graças à complementariedade deste recurso com outros recursos estratégicos, ou seja, o recurso chef de cozinha é o elo que une vários outros recursos estratégicos dos restaurantes e esta complementariedade entre esses vários recursos produz valor pelo efeito sinérgico da atuação conjunta.

O recurso estratégico chef de cozinha tem estreita relação com o processo de desenvolvimento e/ou aquisição de outros recursos: cultura organizacional, 
rede de relacionamento, reputação, inovação e criatividade, recursos financeiros e até mesmo os recursos físicos - equipamentos e ambiente, conforme retrata a Figura 1, e é a partir da junção desses recursos que a VCS pode ser gerada. Este achado corrobora Adegbesan (2009), que argumenta serem os gestores responsáveis por criar valor para a empresa e se diferenciar dos concorrentes por meio da combinação e da complementariedade de recursos.

O primeiro recurso que está associado aos chefs de cozinha é a cultura organizacional - conjunto de valores que determinados membros compartilham dentro de uma organização e que possibilita a esta ser diferente das demais (Robbins, 2005). Noscasospesquisados, estaculturaestáassentada principalmente nos valores pessoais dos chefs e principalmente foi e é comunicada e reforçada com a equipe por estes profissionais.

No Mocotó a hospitalidade é um traço da cultura organizacional que está fortemente ligada à figura do fundador da empresa, Sr. Zé Almeida, e ao chef, Rodrigo Oliveira. O chef Rodrigo Oliveira explica que: "O Mocotó sempre foi um restaurante muito mais inclusivo do que exclusivo, e meu pai sempre foi um grande anfitrião, que tem prazer em servir".

Figura 1: O recurso chef e sua relação com os demais recursos estratégicos

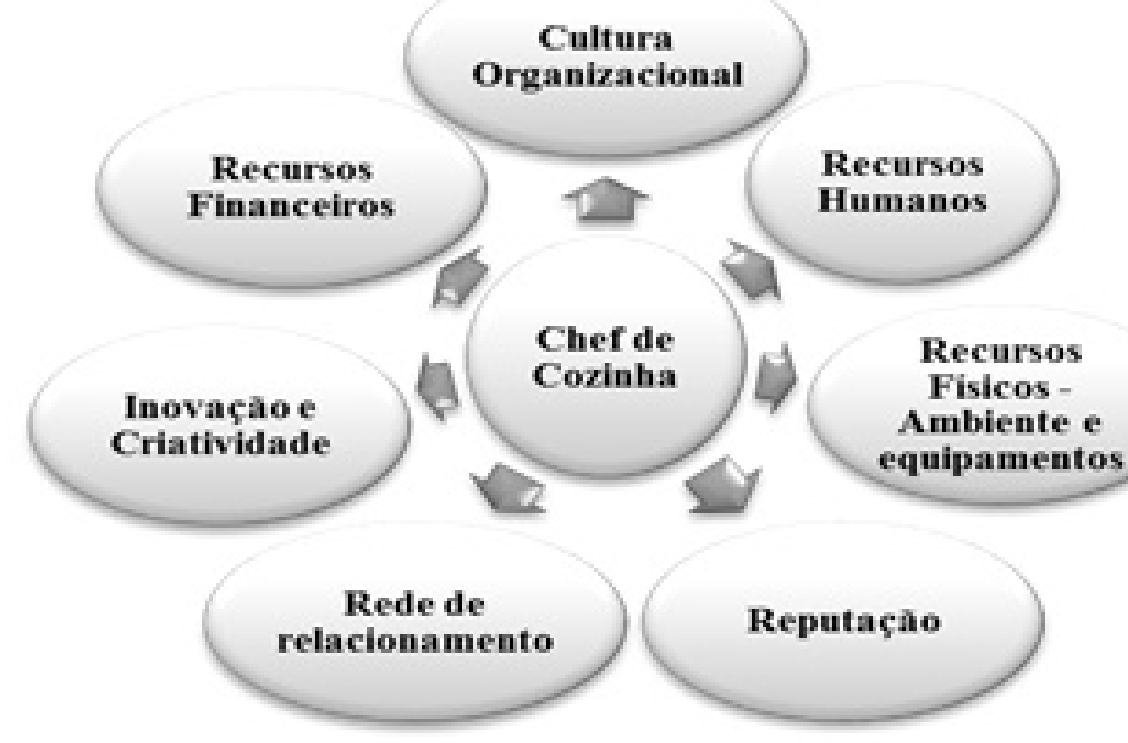

Fonte: Elaboração dos autores (2015).

Além da hospitalidade, é possível perceber outras associações entre chef e cultura organizacional do Mocotó, como as práticas de gestão de recursos humanos. E conquanto Wright et al. (2001) defendam que estas práticas possam 
ser facilmente copiadas, acredita-se que neste caso específico a imitação não pode ocorrer, pois tais práticas estão imbricadas na história da empresa. Por exemplo, o recrutamento de novos empregados se dá exclusivamente por meio de indicação dos antigos funcionários, o que parece gerar um ambiente de confiança e ajuda mútua. Ademais, todo novo funcionário é contratado no mais baixo cargo da hierarquia, mesmo que ele já tenha experiência anterior e, aos poucos, possa ser promovido. Isto permite valorizar e promover os funcionários mais antigos, além de desenvolvê-los e inseri-los na cultura organizacional, corroborando achados de Balazs (2001).

Esta simbiose entre comportamento do gestor e processo de formulação e implementação das estratégias está em consonância com Gimenez (2000) e Pinheiro (1996), ao defenderem que há uma ligação entre as características pessoais do dirigente - personalidade, valores, motivação e intuição - e o processo de administração estratégica das pequenas empresas. Ainda considerando a natureza empreendedora (Moraes et al., 2010) e personalista dos proprietários de micro e pequenas empresas (MPME), os estrategistas que estão à frente dessas empresas têm destacada importância, pois são os condutores do sucesso ou da extinção das mesmas (Fontes Filho \& Nunes, 2010).

No Epice, a cultura organizacional também estava relacionada ao chef Alberto Landgraf. Aqui, cabe destacar o aspecto "militar" encontrado em alguns restaurantes franceses estrelados pelo Guide Michellin, visto que a preparação de cada prato é regida por um conjunto completo e inalterável de regras precisas (Balazs, 2001). Na cozinha do Epice, é proibido música, apelidos e conversas paralelas em um clima de silêncio quase absoluto - até no auge do serviço, pois para o chef Alberto Landgraf (2014):

As conversas tiram sua atenção levando ao erro, cozinhar é um ato de carinho, um ato de amor pelos alimentos e as pessoas que irão comer o que você cozinhou, então é vital que você esteja focado nisso.

Já no Astrid y Gaston os valores cultivados desde a sua inauguração até os dias atuais são: comprar ingredientes de produtores locais, cozinhar diariamente, conhecer os clientes pelo primeiro nome e transformar as pessoas com quem trabalha em uma família. Estes valores estão fortemente relacionados à figura 
do fundador do restaurante Gaston Acurio, que foi o chef de cozinha até meados dos anos 2000. O chef Diego Muñoz, que assumiu o comando da cozinha em 2011, deu início a uma mudança da cultura organizacional. Diego Muñoz aprendeu nas cozinhas dos estrelados restaurantes em que trabalhou a ser muito exigente, disciplinado, a manter a ordem. No início este novo estilo de liderança acarretou mudanças na equipe:

Cuando yo entré y planteamos el primer menú la gente estaba exhausta. Para poner en marcha un menú como los que hacemos ahora había que ser estricto, muy disciplinado, hasta drástico. Y ahí empezaron los problemas, la gente se quejaba, algunos empezaron a renunciar.

Há indícios que esta nova cultura organizacional que vem sendo desenvolvida desde a contratação de Diego Muñoz será mantida, pois Gastón Acurio afirma que: Diego es una persona muy metódica, muy ordenada, yo soy una persona más espontánea. Qué bueno que sea así, porque en el momento en que está el restaurante necesita de ese orden estricto, casi militar.

A segunda categoria de recursos é formada por recursos humanos, que como apregoa a literatura, são basicamente intangíveis e se referem ao conhecimento, à confiança, à capacidade de inovar dos funcionários, bem como à capacidade gerencial (Barney, 1991; Grant, 1991; Pike, Roos \& Marr, 2005). A reputação e a rede de relacionamento dos três chefs de cozinha estudados estão fortemente relacionadas à atração eà retenção de jovens talentos-estudantes de gastronomia e o caso mais emblemático foi o do Astrid y Gaston, que garças à reputação construída por Diego Muñoz e Gastón Acurio atraíram outros chefs de renome, como o mexicano Emilio Macias, que trabalha como sous chef do restaurante, o sommelier Julio Barluenga e o diretor do salão Luis García, os quais vieram do premiado restaurante espanhol El Bulli. Estes achados corroboram com Coff e Kryscynski (2011) que argumentam que ter recursos humanos de alta qualidade pode atrair outros empregados competentes e que a rede de relacionamento pessoal de alguns empregados pode também ser um modo de recrutar novos talentos. Ademais, as empresas com recursos humanos mais qualificados estão mais bem posicionadas para criar outros recursos caracterizados pela: especificidade, complexidade social e ambiguidade casual, tornando-os muito difíceis de imitar (Coff \& Kryscynski, 2011). 
Outra categoria de recursos analisada é a reputação junto ao cliente e a reputação junto ao fornecedor (Barney, 1991; Grant; 1991; Pike, Roos \& Marr, 2005). No caso específico dos chefs de cozinha e dos restaurantes de alta gastronomia, é importante ressaltar também a reputação junto à mídia especializada, jornalistas e guias gastronômicos.

No que se refere à clientela, a reputação torna-se ainda mais importante neste mercado de alta gastronomia, pois os produtos são sempre associados ao nome do autor (chef) e essa relação entre criador e produto torna os produtos únicos - e o nome do chef passa a ser um importante capital não só intelectual, mas também financeiro (Leschziner, 2007).

Neste tipo de restaurante, a reputação está assentada na autenticidade, que exige duas qualidades que coexistem de modo paradoxal: conformidade a um estilo e originalidade. Mudar constantemente de estilo torna um criador inautêntico. No entanto, a fidelidade a um estilo sem um elemento de novidade pode parecer como nada mais que uma cópia da criação de outra pessoa (Leschziner, 2007). O caso do Restaurante Mocotó segue nesse sentido, visto que, ao mesmo tempo em que a culinária é nordestina (conformidade com um estilo), ela é também original por apresentar receitas tradicionais sertanejas elaboradas com técnicas e apresentações modernas. No Epice é possível perceber uma conformidade na concepção (usar ingredientes menos valorizados na alta gastronomia) e na apresentação (estética minimalista) das receitas elaboradas de modo original. No Astrid y Gaston a autenticidade está em servir a comida tradicional peruana usando também técnicas modernas e apresentá-la em forma de menu degustação, aliada ao storytelling.

Nos três casos estudados os chefs têm um engajamento político-social que os projeta na mídia e, consequentemente, aumenta a reputação. Esta boa reputação, junto à mídia especializada, pode ser comprovada tanto pelos prêmios recebidos pelos restaurantes e pelos chefs de cozinha quanto pelas críticas escritas nos principais meios de comunicação.

É possível perceber uma associação entre recursos reputacionais e recursos relacionais, já que uma boa reputação pode desenvolver ou aumentar a rede de relacionamento não apenas da empresa, mas também do chef, ao mesmo tempo 
ISSN: 1983-7151

em que a rede de relacionamento pode aumentar a reputação do restaurante e do seu chef. Percebe-se assim que entre estes recursos há o que Barney (1991) conceitua como ambiguidade causal, que dificulta a imitação dos recursos pelos concorrentes. Tanto os recursos relacionais quanto os reputacionais estão pautados na figura dos chefs de cozinha destas empresas graças à notoriedade que possuem na sociedade atual.

Por recursos relacionais entendem-se os acordos de parcerias com fornecedores, centros de pesquisa ou universidades, bem como as relações com órgãos de regulamentação (Pike, Roos \& Marr, 2005). No caso dos restaurantes, Balazs (2002) acrescenta as relações entre chefs e clientes, pois os primeiros acreditam que os clientes devem ser tratados como pessoas muito importantes e, para isso, os chefs fazem esforço para conhecê-los e garantir a satisfação dos mesmos. Nos casos estudados, foi possível perceber também a importância da rede de relacionamento com outros chefs e com críticos e jornalistas.

Com os fornecedores, o relacionamento objetiva desenvolver a cadeia produtiva e divulgar o trabalho deles, além de ter acesso a produtos de qualidade que suportem as estratégias de negócios dos restaurantes. Ademais, o relacionamento entre chefs e fornecedores permite aos primeiros serem pioneiros no conhecimento e na introdução de novos ingredientes no mercado (Leschziner, 2007) e o desenvolvimento de pesquisas e novos equipamentos. Já com os críticos gastronômicos, a rede de relacionamento tem o intuito de construir uma opinião favorável sobre o restaurante, já que por ser um gênero jornalístico opinativo sobre o trabalho de um chef ou restaurante a crítica gastronômica pode influenciar a demanda e afetar o valor e a frequência aos restaurantes (Barbosa, 2010).

Por fim, os relacionamentos com colegas de profissão permitem aos chefs conhecerem e se familiarizarem com o estilo destes colegas de profissão, que são considerados também profissionais de vanguarda e são pioneiros em importar novas ideias para o mercado gastronômico, havendo assim uma associação entre os recursos relacionais e os recursos tecnológicos de inovação dos chefs de cozinha (Stierand \& Lynch, 2008).

Os recursos tecnológicos são classificados em tangíveis - sistemas operacionais, estoque de tecnologias, como patentes, marcas registradas, 
direitos autorais e segredos comerciais (Grant; 1991; Hall, 1992); e intangíveis - ideias, capacidade científica, capacidade de inovar (Grant; 1991; Hall, 1992). Como não há como patentear receitas e, portanto, as inovações produzidas pelos chefs podem ser rapidamente copiadas ou imitadas, um processo contínuo de inovação é apontado como condição sine qua non para manter a vantagem competitiva (Ottenbacher \& Harrington, 2007; Hu, 2010). Na alta gastronomia, a inovação e a criatividade foram introduzidas pelo movimento da nouvelle cuisine (Manfred, 2008), sendo a verdadeira ruptura do movimento o modo dos chefs lidarem com a inovação.

O chef de cozinha é o responsável pelo processo de criação e inovação nos restaurantes gastronômicos, apesar deste processo contar com a colaboração de outras pessoas, sejam elas funcionários ou colaboradores externos. Dos recursos tecnológicos tangíveis foi possível identificar algumas receitas e técnicas culinárias de preparação criadas no Mocotó pelo chef Rodrigo Oliveira e Epice por Alberto Landgraf. No Astrid y Gaston, ao contrário dos outros casos estudados, a criatividade e a inovação do chef são muito mais conceituais e abstratas. Não foi possível identificar nenhuma técnica ou equipamento que tenha sido desenvolvido no restaurante. A criação e a inovação neste caso se manifestam no conceito do restaurante e na maneira de servir, que vem mudando paulatinamente, corroborando com Dória (2006), para quem o chef inovador é aquele que mobiliza competências e inicia uma nova onda de transformações culturais socialmente contextualizadas.

No Mocotó, Rodrigo Oliveira foi o autor de dois clássicos atualmente copiados em todo o Brasil: o sorvete de rapadura e os dadinhos de tapioca, cuja autoralidade (capacidade do chef de produzir os pratos com alguma originalidade, ligando-os a suas crenças e preferências culinárias) é reconhecida tanto por chefs quanto pelo mercado consumidor. O próprio chef reconhece e se alegra com a fama e a propagação que o dadinho de tapioca alcançou: "[...] ele está no Pará, no Amazonas, no Rio Grande do Sul e está na Espanha também. Foi um grande feito, porque é uma receita tão simples, né? Tem 3 ingredientes: tem queijo, leite e tapioca. Nada mais".

Os recursos tecnológicos tangíveis são decorrentes dos recursos tecnológicos intangíveis que no Mocotó se refere à capacidade dos chefs de criar e inovar. $\mathrm{O}$ 
termo criatividade deriva do latim "creare" e significa criar, inventar, fazer algo novo e pode ser conceituado como a geração de ideias por meio de conceitos, teorias e processos que se apresentam ao longo da história. Na profissão do chef a criatividade é a chave para a modernização (Horng \& Lee, 2009). Os autores defendem também que a cooperação e a competitividade entre os chefs incentivam na criatividade culinária individual e podem aumentar a competitividade entre os restaurantes.

O processo criativo dos chefs Diego Muñoz e Rodrigo Oliveira pode ser descrito como orgânico e mais informal, resultados que seguem em linha com os achados de Ottenbacher e Harrington (2007). O chef Rodrigo afirma que:

Mas a gente exercita a criatividade de muitas maneiras. Primeiro, a criação livre. A criação pode ser uma receita, pode ser um produto, pode uma história, uma música, um prato, enfim. E outra maneira de exercitar a criatividade é pensar em como fazer melhor.

Já o processo de criação do chef Alberto Landgraf é mais preciso e ordenado, corroborando pesquisa de Slavich, Cappetta e Salvemini (2014), que investigaram chefs no contexto italiano. Para o chef Alberto Landgraf: "Criação tem que ter método. Você tem que ter um método porque eu também aprendi que criação não é uma disciplina de acertos. É uma disciplina de erros".

O processo racional e estruturado do chef é legitimado por Lunardelli (2012, p.65), quando defende que "[...] a visão romântica do chef, como aquele que concebe pratos e sabores a partir de sopros de inspiração, deve ser repensada". Para o chef existem duas possibilidades de criar uma nova receita: por meio de uma referência, e normalmente é o trinômio carboidrato, proteína e legume; ou escolher um ingrediente e trabalhar elementos de sabor, textura e temperatura.

O processo é muito bem pensado. O chef Alberto Landgraf faz vários estudos de uma receita, anota tudo em cadernos ou folhas avulsas e afirma que: "Primeiro, imagino o prato a partir de uma composição de ingredientes e, depois, vou para o fogão fazer os testes". Este processo pode ser comprovado ao se analisar a Figura 2. 
Figura 2: Processo de criação de uma receita do chef Alberto Landgraf
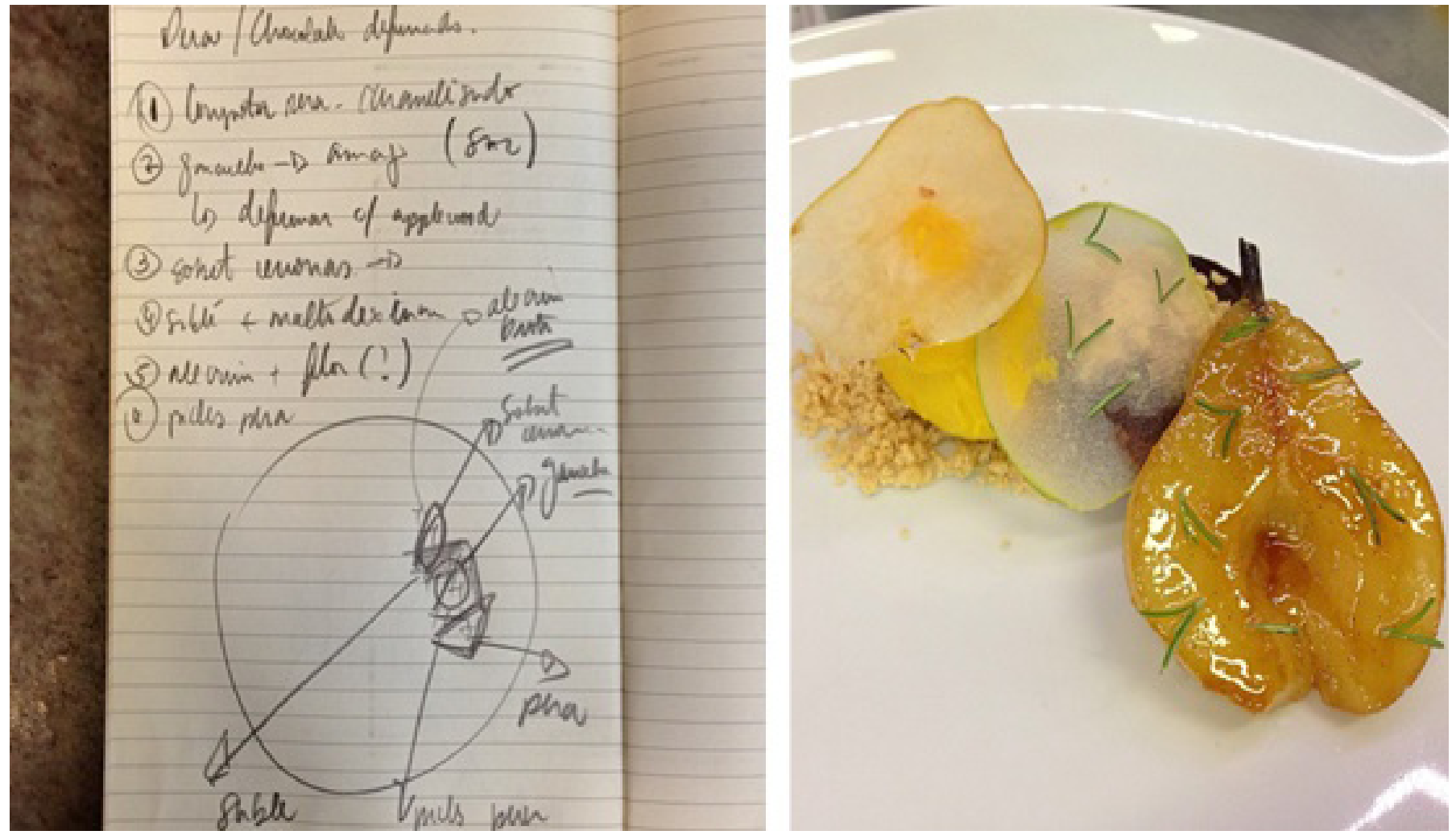

Fonte: Fotos publicadas no facebook do Chef Alberto Landgraf (2014).

Este método de criação também corrobora achados anteriores (Ottenbacher \& Harrington, 2007; Svejenova, Mazza \& Planellas, 2007; Slavich, Cappetta \& Salvemini, 2014), que afirmam que a criatividade dos chefs é baseada na busca pelo contraste de sabor - doce, ácido, salgado; textura - crocante versus macio; formas, cor e temperatura quando da criação de uma nova receita.

Há no processo de criação e inovação dos chefs uma dimensão mais concreta - novos produtos e serviços - e outra abstrata - novas maneiras de pensar a comida, ou seja, o que se come e como se come (Stierand \& Lynch, 2008). Nos três casos estudados foi possível perceber ambas as dimensões. A dimensão mais concreta se manifestou por meio do uso de ingredientes pouco valorizados, na apresentação estética dos pratos e na introdução de novos conceitos - como a cozinha totalmente à vista do cliente na inauguração do Astrid y Gaston ou a não cobrança da água servida no Epice. A dimensão abstrata se manifestou por meio de transformar a gastronomia em um instrumento de discurso socioambiental, de valorização das culinárias regionais e na concepção de menus degustação como uma experiência holística que abrange diversas artes - música, artes plásticas, literatura e teatro. 
Os chef de cozinha estudados tiveram também papel relevante tanto na aquisição quanto no desenvolvimento dos recursos físicos tangíveis dos restaurantes, especificamente na concepção do ambiente de serviço e na aquisição e no desenvolvimento de equipamentos e utensílios usados nas cozinhas.

O ambiente de serviço está associado à satisfação dos clientes, ao processo de escolha e ao retorno aos restaurantes gastronômicos e ao desempenho dos mesmos (Auty, 1992; Kivela, 1997; Mattila, 2001; Johns \& Kivela, 2001; Chossat \& Gergaud, 2003; Salazar, 2006). É mister que haja um alinhamento entre o ambiente de serviço do restaurante e a proposta deste. Por exemplo, o ambiente do restaurante Mocotó, apesar de planejado, é bastante simples, mas retrata a cultura e a hospitalidade sertaneja.

Nos três casos estudados os chefs são os responsáveis por trazer para a cozinha dos restaurantes equipamentos modernos. Todas as cozinhas são equipadas com produtos de última geração, como termocirculadores, Gastrovac, Termomix, Pacojet, Sous Vide - equipamentos estes, em sua maioria, desenvolvidos na Espanha na década passada, fruto de parcerias entre chefs espanhóis e governo. Estes equipamentos representam novas tecnologias e estas novas tecnologias são um fator importante para a inovação, pois podem ser influenciadas tanto pelos chefs como podem influenciar suas práticas e processo de aprendizagem (Stierand \& Lynch, 2008).

Por fim, a última categoria de recursos relacionada aos chefs é a dos recursos financeiros e que se refere à capacidade de levantar capital e a habilidade em gerar fundos internamente (Grant, 1991; Pike, Roos \& Marr, 2005).

Apesar da importância deste tipo de recurso e de ter sido mencionado transversalmente pelos chefs Rodrigo Oliveira e Alberto Landgrafdos restaurantes Mocotó e Epice, respectivamente, foi apenas no caso do restaurante Astrid y Gaston que os recursos financeiros se revelaram muito importantes para gerar vantagem competitiva sustentável.

No Mocotó, os recursos financeiros não se mostraram tão essenciais para as estratégias por serem estas, em grande parte da história da empresa, emergentes e, portanto, terem sido elaboradas de modo incremental usando sempre capital 
próprio devido à crença do Sr. Zé Almeida de não se endividar. Já no Epice, o capital usado para iniciar o empreendimento também foi relativamente baixo e dividido entre os sócios.

Porém, no caso do restaurante Astrid y Gaston, os recursos financeiros foram muito importantes no início do restaurante e, em 2014, na mudança para a nova sede - Casa Moreyra. Para a abertura do restaurante, o capital necessário foi alavancado com a família de Gastón Acurio. Em 2014, pela magnitude da estratégia do projeto Casa Moreyra, que custou seis milhões de dólares, além de capital próprio, houve também aporte do capital de terceiros, no caso específico da empresa espanhola Telefónica e conseguido graças à boa reputação e à rede de relacionamento de Gastón Acurio, ex-chef e proprietário do restaurante.

\section{CONSIDERAÇÕES FINAIS}

O objetivo deste trabalho foi o de analisar como o chef de cozinha de restaurantes gastronômicos da América Latina pode gerar vantagem competitiva sustentável. O fascínio pelos chefs de cozinha é um fenômeno identificado em todo o mundo. Em todos os três casos estudados este recurso foi identificado como primordial para a concepção e consecução das estratégias que busquem atingir VCS. Foram os chefs os responsáveis por usarem de modo conjunto e complementar vários recursos, como cultura, recursos humanos, físicos, financeiros, tecnológicos, relacionais e reputacionais, para uma identidade distinta para suas empresas, diferenciando-as da concorrência, corroborando os achados de Slavich, Cappetta e Salvemini (2014).

A criatividade dos chefs estudados corrobora outras pesquisas centradas neste profissional que atribuem a esta uma das razões de sucesso de alguns restaurantes estrelados (Svejenova, Mazza \& Panellas, 2007). Cabe ressaltar que a criatividade na gastronomia não se limita apenas a novos produtos e/ou novos serviços, mas inclui também novas maneiras de pensar a comida, ou seja, o que se come e como se come (Stierand \& Lynch, 2008). Cada chef produziu um estilo próprio de cozinha, que tem uma história para contar e para tanto desenvolveu e/ou adquiriu os recursos estratégicos necessários para isso. 
Os processos de criação são, em alguns aspectos, semelhantes entre si, mas apresentam também algumas diferenças. As semelhanças se referem aos fatores que auxiliaram os chefs neste processo: recursos físicos, como equipamentos, utensílios; recursos humanos, como funcionários bem qualificados e treinados; e uma "mente aberta" (Horng \& Lee, 2009). As fontes de inspiração dos chefs pesquisados também são as mesmas: visitas a outros chefs; leitura de livros de gastronomia; visitas a mercados, viagens e experiências de funcionários e clientes. A diferença se refere ao modo como o processo ocorreu. Enquanto o processo de Rodrigo Oliveira e Diego Muñoz pode ser descrito como mais orgânico e informal, em linha com a pesquisa de Ottenbacher e Harrington (2007) que investigaram o contexto francês, o processo de Alberto Landgraf é mais preciso e ordenado, assemelhando-se aos achados do estudo de Slavich, Cappetta e Salvemini (2014), que investigaram chefs no contexto italiano.

Os achados desta pesquisa permitem concluir que o principal recurso dos restaurantes gastronômicos atualmente é o chef de cozinha. Desde a nouvelle cuisine que este ganhou notoriedade e hoje é alçado ao posto de celebridade.

\section{REFERÊNCIAS}

Adegbesan, J. A. (2009). On the origins of competitive advantage: strategic factor markets and heterogeneous resource complementarity. Academy of Management Review, 34(3): 463-475

Almeida, I. O., Barbosa, M. L. A. \& Salazar, V. S. (2013). Influências do Pessoal de Linha de Frente na Experiência de Consumo: um Estudo a Partir do Encontro de Serviços em Restaurante Gastronômico. In: Anais... VI CLAV - Congresso Latino-Americano no Varejo, 6 , São Paulo.

Amit, R. \& Schoemaker, P. J. H. (1993). Strategic assets and organizational rent. Strategic Management Journal, 14(1): 33-46.

Atala, A. \& Dória, C. A. (2008). Com unhas, dentes e cuca: prática culinária e papo-cabeça ao alcance de todos. Senac, São Paulo.

Auty, S. (1992). Consumer choice and Segmentation in the Restaurant Industry. The Service Industries Journal, 12(3): 324-339.

Balazs, K. (2001). Leadership Lessons from France's Great Chefs. Organizational Dynamics 30(2): 134-148. 
Balazs, K. (2002). Take one entrepreneur: The Recipe for Success of Frances's Great Chefs. European Management Journal, 20(3): 247-259

Barbosa, M. (2010). Obsessões de um clássico. Revista Prazeres da Mesa, Editora 4 Capas, São Paulo n.83.

Barney, J. B. (1986). Strategic factor markets: Expectations, luck, and business strategy. Management Science, 32(1): 1231-1241.

Barney, J. B. (1991). Firm resources and sustained competitive advantage. Journal of Management, 17(1): 99-120.

Barney, J. B. (2002). Gaining and Sustaining Competitive Advantage. 3. ed. Prentice-Hall, New Jersey.

Barney, J. B. (2001). Is the resource-based view a useful perspective for strategic management research? Yes. The Academy of Management Review, 26(1): 41-56.

Barney, J. B. (2001). Resource-based theories of competitive advantage: A ten-year retrospective on the resource-based view. Journal of Management, 27(1): 643-650.

Barney, J. B. \& Hesterly, W. (2004). Economia das organizações: entendendo a relação entre as organizações e a análise econômica. In: Clegg, S., Hardy, C. \& Nord, D. (Orgs.) Handbook de estudos organizacionais, São Paulo: Atlas: 131-179.

Birdir, K. \& Pearson, T. E. (2000). Researches chef's competencies: a Delphi approach. International Journal of Contemporary Hospitality Management, 12(3): 205-209.

Brandão, H. A. \& Pereira, F. A. (2010). Fontes de Vantagem Competitiva Sustentável do Pólo de Gastronomia de Pernambuco: uma Visão Baseada em Recursos. In: Anais... XXXIV Encontro da ANPAD, Rio de Janeiro.

Carneiro, J. M. T., Cavalcanti, M. A. F. D. \& DA Silva, J. F. (1999). Os determinantes da Sustentabilidade da Vantagem Competitiva na Visão Resource Based. In: Anais... XXIII Encontro da ANPAD, Foz do Iguaçu

Chossat, V. \& Gergaud, O. (2003). Expert opinion and gastronomy: the recipe for success. Journal of Cultural Economics, 27(1): 127-141.

Creswell, J. W. (2010). Projeto de pesquisa: métodos qualitativo, quantitativo e misto. 3. ed. Artmed/Bookman, Porto Alegre.

Creswell, J. W. (2007). Qualitative inquiry and research design: choosing among five approaches. 2. ed. Sage Publications, Thousand Oaks. 
De Wit, B. \& Meyer, R. (2004). Strategy: process, content, context. 3. ed. Thomson, London.

Dierickx, I. \& Cool, K. (1989). Asset stock accumulation and sustainability of competitive advantage. Management Science, 35(12): 1504-1513.

Dória, C. A. (2006). Estrelas no céu da boca: escrito sobre culinária e gastronomia. Editora SENAC, São Paulo.

Dória, C. A. (2014). Formação da culinária brasileira: escritos sobre a cozinha inzoneira. Três Estrelas, São Paulo.

Durand, R., Rao, H. \& Monin, P. (2007). Code and conduct in French Cuisine: Impact of code changes on external evaluations. Strategic Management Journal, 28(1): 455-472.

Flick, U. (2009). Introdução à pesquisa qualitativa. 3.ed. Artmed/Bookman, Porto Alegre.

Fontes Filho, J. R. \& Nunes, G. S. A. (2010). O Estrategista da Micro, Pequena e Média Empresa Privada Brasileira. RBGN - Revista Brasileira de Gestão de Negócios, 36(2): 271-288.

Galbreath, J. \& Galvin, P. (2004). Which resources matter? A fine-grained test of the resourcebased view of the firm. Academy of Management Best conference paper, proceedings.

Grant, R. M. (1991). The Resource-Based Theory of competitive advantage: Implications for strategy formulation. California Management Review, 33(3): 114-135.

Godoy, A. S. (1995). Pesquisa Qualitativa: tipos fundamentais. Revista de Administração de Empresas - RAE, 35(3): 20-29.

Hall, R. (1992). The strategic analysis of intangible resources. Strategic Management Journal, 13(2): 135-144.

Hetzel, P. (2004) Vers une Approche Expérientielle de la Haute Cuisine Française: Iorsque marketing rime avec construction du sens. Revue Française du Marketing, 196: 67-77.

Horng, J. S. \& Lee, Y. C. (2009). What enviromental factors infuence creative culinary studies? International Journal of Contemporary Hospitality Management, 21(1): 100-117.

$\mathrm{Hu}$, M. L. (2010). Discovering culinary competency: an innovative approach. Journal of Hospitality, Leisure, Sports and Tourism Education, 9(1): 65-72.

Johns, N. \& Kivela, J. J. (2001). Perceptions of the first time restaurant customer. Food Service Technology, 1(1): 5-11.

Johnson, C., Surlemond, B., Nicod, P. \& Revaz, F. (2005). Behind the stars: a concise typology of Michelin Restaurants in Europe. Cornell Hotel and Restaurant Administration Quarterly, 46(2): 170-187. 
Kivela, J. J. (1997). Restaurant marketing: selection and segmentation in Hong Kong. International Journal of Contemporary Hospytality Management, 9(3): 116-123.

Kraaijenbrink, J., Spender, J.C. \& Groen, A.J. (2010). The resource-based view: a review and assessment of its critiques. Journal of Management, 36 (1):349-372.

Lane, C. (2011). Culinary culture and globalization. An analysis of British and German Michelin-starred restaurants. The British Journal of Sociology, 62(4): 696-717.

Leschziner, V. (2007). Kitchen stories: patterns of recognition in contemporary high cuisine. Sociological Forum, 22(1): 78-102.

Lewis, R. C. (1981). Restaurant advertising: appeals and Consumers' Intentions. Journal of Advertising Research, 21 (5).

Lockett, A., Thompson, S. \& Morgenstern, U. (2009). The development of the resourcebased view of the firm: a critical appraisal. International Journal of Management Review, 11(1):9-28.

Lunardelli, T. (2012). Estética do gosto. Dissertação (Mestrado em Artes) - Programa de PósGraduação em Artes, Universidade Estadual Paulista, São Paulo.

Manfred, W. L. (2008). As revoluções de Ferran Adrià: o chef de cozinha que transformou a culinária em arte. L\&PM, Porto Alegre.

Mattila, A. S. (2001). Emotional bonding and restaurant loyalty. Cornell Hotel \& Restaurant Administration Quarterly, 42(6): 73-79.

Merriam, S. B. (1998). Qualitative research and case study applications in education. JosseyBass, San Francisco

Miller, D. \& Shamsie, J. (1996). The resource-based view of the firm in two environments: the Hollywood Film Studios from 1936 to 1965. Academy of Management Journal, 39(3): 519-543.

Moraes, W. F. A., Albuquerque, M. A. V., Ortiz, F. H. L. \& Campos, A. O. (2010). Processo Decisório Estratégico de Dirigentes de Micro, Pequenas e Médias Empresas. In: Anais... VI EGEPE Encontro de Estudos sobre Empreendedorismo e Gestão de Pequenas Empresas, Recife.

Murphy, J. \& Smith, S. (2009). Chefs and suppliers: An exploratory look at supply chain issues in an upscale restaurant alliance. International Journal of Hospitality Management, 28(1): 212- 220.

Ottenbacher, M. \& Harrington, R. J. (2007). The innovation development process of Michelin-starred chefs. International Journal of Contemporary Hospitality Management, 19(6): 444-460. 
Ottenbacher, M. \& Harrington, R. J. (2008). Institutional, cultural and contextual factors: potencial drivers of the culinary innovation process. Tourism and Hospitality Research, 9(3): 235-249.

Patton, M. Q. (2001). Qualitative research and evaluation methods. Sage Publication, California.

Peteraf, M. A. (1993). The cornerstones of competitive advantage: a resource-based view. Strategic Management Journal, 14(3): 179-188.

Pettigrew, A. M. (1987). Context and action in transformation of the firm. Journal of Management Studies, 24(6): 649-670.

Pike, S., Roos, G. \& Marr, B. (2005). Strategic management of intangible assets and value drivers in R\&D organizations. R\&D Management, 35(2): 111-124.

Pinheiro, M. (1996). Gestão e desempenho das empresas de pequeno porte: uma abordagem conceitual e empírica. Tese (Doutorado em Administração). Faculdade de Economia, Administração e Contabilidade. São Paulo: Universidade de São Paulo.

Rao, H., Monin, P. \& Durand, R. (2003). Institutional change in toque ville: nouvelle cuisine as an identity movement in France. American Journal of Sociology, 108(4): 795-843.

Robbins, S. P. (2005). Comportamento organizacional. Pearson Prentice Hall, São Paulo.

Scavone, N. (2007). Discursos da gastronomia brasileira: gêneros e identidade nacional postos à mesa. Dissertação (Mestrado em educação) Universidade Federal do Rio Grande do Sul (UFRS). Porto Alegre.

Schmitt, B. H. \& Simonson, A. (2000). A Estética do Marketing. Nobel, São Paulo.

Slavich, B., Cappetta, R. \& Salvemini, S. (2014). The experience of Italian haute cuisine chefs. International Journal of Arts Management, 16(2): 29-41.

Stierand, M. \& Lynch, P. (2008). The art of creating culinary innovations. Tourism and Hospitality Research, 8(4): 337-350.

Surlemont, B., Jonhson, C. (2005). The role of guides in artistic industries: the special case of the "star system" in the haute-cuisine sector. Managing Service Quality, v.15 (6).

Svejenova, S., Mazza, C. \& Planellas, M. (2007). Cooking up change in haute cuisine: Ferran Adriá as an institutional entrepreneur. Journal of Organizational Behavior, 28(1): 539-561.

Taylor, S. J. \& Bogdan, R. (1984). Introduction to qualitative research methods: the search for meanings. John Wiley \& Sons: 123- 145 
This, H. \& Gagnaire, P. (2010). Cozinha: uma questão de amor, arte e técnica. Editora Senac, São Paulo.

Vasconcelos, F. C. \& Cyrino, A. B. (2000). Vantagem Competitiva: os modelos teóricos atuais e a convergência entre estratégia e teoria organizacional. Revista de Administração de Empresas - ERA, 40(4): 20-37

Walker, J. R. \& Lundberg, D. E. (2003). O restaurante: conceito e operação. Bookman, Porto Alegre.

Wernerfelt, B. (1984). A resource-based view of the firm. Strategic Management Journal, 5(1): 171-180.

\section{CONTRIBUIÇÃO DOS AUTORES NA CONSTRUÇÃO DO ARTIGO}

SALAZAR: Elaboração do problema de pesquisa e dos procedimentos metodológicos; coleta e análise de dados; escrita dos resultados e das considerações finais.

MORAES: Revisão e orientação de todo o texto; Escrita do artigo.

PEREIRA: Revisão do texto; Operacionalização do software de análise Atlas t.i; Escrita do artigo. 